\title{
Sensory impairment and mental health
}

\author{
Margaret du Feu \& Kenneth Fergusson
}

\begin{abstract}
Sensory impairment is often regarded from a medical/disability point of view and its effects on mental health can be poorly recognised. Communication is a key issue for deaf and deaf-blind people and difficulties here underlie developmental, psychological and emotional problems and delay or prevent appropriate assessment and treatment. Children may have additional problems associated with the cause of their sensory impairment and need early multi-disciplinary intervention. Emotional and practical support is needed for families to make fully informed choices. Those with and without sensory impairment need the same access to mental health services and this is particularly difficult to achieve for deaf and deaf-blind people. Local and specialist teams need to work together to implement the National Service Framework for this vulnerable patient group.
\end{abstract}

Visual and hearing problems are seen as medical problems and as disabilities. However, the main concerns of those affected by the total or partial absence of sight and/or hearing are usually how to live, how to learn and how to communicate. Their difficulties are often as much to do with society's attitudes towards them as with the direct effect of sensory impairment. Helen Keller (1948) said that blindness cut her off from things and deafness from people. She wrote 'I have found deafness to be a much greater handicap than blindness. Deafness ... cheats many of their birthright to knowledge' (quoted in Grant, 1987) The effect of sight and/or hearing loss depends on the degree of loss and the age at and speed of onset.

Early onset of significant visual or hearing impairment can have a profound effect on a child's development, with adverse consequences for mental health, both in childhood and adult life.

Sudden loss of a sense, owing to illness or accident, can devastate a person's life if appropriate help, both practical and psychological, is not given.

Mild but progressive sight and hearing losses are common with ageing. They may be unnoticed for some time, but then have a serious cumulative effect on a person's communication, confidence and independence.

\section{Deafness}

Hearing loss affects more than 8 million people in the UK. About 5 million people could benefit from hearing aids, but over half of these are reluctant to use an aid because of the associated stigma. Hearing aids are often inefficient and even painful to use, and many NHS aids are left unworn. The introduction of digital hearing aids and the wider availability of hearing therapy should improve this situation. Because of frustrations in communication and the invisible nature of the disability, deafness is not regarded as tolerantly as is loss of sight. Access to services by deaf people can be seriously curtailed. Many deaf people avoid medical appointments or do not understand what their general practitioner says.

About 50000 people who have been deaf from early life have British Sign Language (BSL) as their first or preferred language. Most of them regard themselves as members of a cultural and linguistic minority, the deaf community, not as part of a disabled group. They have a national network of clubs and associations and the British Deaf Association is their main representative organisation. There is a strong tradition of deaf theatre, poetry, story-telling and history. People from deaf families, who form the core of the deaf community, and many deaf people from hearing families, find confidence, support, self-esteem and a positive identity within the community and this has a protective effect on mental health.

Deaf people can benefit from the more-positive attitudes towards them that arise from deafawareness training, and from environmental and human aids (Box 1).

Margaret du Feu has been the consultant psychiatrist for the Birmingham mental health service for deaf people (National Deaf Mental Health Services (Birmingham), Denmark House, Queen Elizabeth Psychiatric Hospital, Mindelsohn Way, Edgbaston, Birmingham B15 2QZ, UK) since its inception in 1991. She is deafened from cochlear otosclerosis, and had a cochlear implant in 1999. Special interests include mental health prevention work and enduring mental illness. She was a trustee of the Royal National Institute for the Deaf (RNID) between 1996 and 2001. Kenneth Fergusson has been research assistant at the Queen Elizabeth Psychiatric Hospital's Deaf Mental Health Services since 1996. He is the main author of an extensive bibliography on deaf cultural and mental health issues. He is currently involved in research relevant to service development. 


\section{Box 1 Aids that deaf people need}

Alerting

Vibrating alarm clocks

Lights or vibrating pagers for phones, doorbells, smoke/fire alarms and baby monitors

Communication

Lip speakers, speech/text equipment

BSL interpreters

Telephone:

amplifiers

loops

textphones

videophones for BSL

Information

Visual displays for:

travel information

paging in doctors' waiting rooms

Television/video:

loops

subtitles

BSL interpretation

BSL information videos

\section{Mental health service provision for deaf people}

Mental health care for deaf people is often poor. In the past, many deaf people with poor written, spoken or signed language skills were in institutional care, often with no appropriate communication or formal diagnosis (Denmark, 1985, 1994). Over the past 50 years, specialist mental health services for deaf people have been developed in many parts of the world. Dr John Denmark opened his service at Whittingham Hospital, Preston, in the 1960s, where he established the principles of providing assessment and treatment in the deaf person's own language, with an understanding of his or her social and cultural background. There are now specialist deaf mental health services in Manchester (including Prestwich and Bury), London and Birmingham (Box 2). They have multidisciplinary teams of deaf and hearing people that provide both in-patient and outreach services across the UK.

Although clinicians within these services have interests in most psychiatric sub-specialities, there are many groups of deaf people for whom there is no specific provision. These include patients who need learning disability, mother-and-baby, olderadult and comprehensive psychotherapy services.

Many people with learning disability have unrecognised deafness and lack appropriate communication skills. Deaf people may have unassessed or misdiagnosed learning disability, because poor verbal IQ tests can, inaccurately, give a low overall IQ score.

Deaf mothers may have been deprived of appropriate family experiences to prepare them for parenting. Poor access to services may have left them without basic knowledge and coping skills.

Deaf older adults who use sign language often belong to a supportive peer group but, as health problems accumulate, they risk becoming increasingly isolated. Few residential and nursing homes or psychogeratric services have experience with deaf people who sign.

The general adult deaf services mentioned above provide psychotherapy, but access to this is usually limited by the patient's geographical location. Deaf individuals working as counsellors in local areas may be relatively unsupported. There is a pressing need for wider availability of psychotherapeutic interventions.

Many deaf offenders are referred for assessment, including fitness to plead, and treatment. Rampton Hospital (Roberts, 1990) provides for most deaf patients who require high-security accommodation and the Mayflower Hospital, Bury (Box 2) provides a medium-security service which, at present, is only for men. A national strategy is being developed for forensic services for deaf offenders, as many are managed inappropriately by the criminal justice system.

The National Health Service (NHS) Executive is currently undertaking a review of mental health service provision for deaf people, as recommended by the Daniel Joseph Inquiry (Mishcon et al, 2000) so that the National Service Framework can be delivered (Department of Health, 2002). This will

\section{Box 2 Useful addresses}

John Denmark Unit, Mental Health Services of Salford, Bury New Road, Prestwich M25 3BL. Tel: 0161772 3432; Minicom: 161772 3407; fax: 01617985853

Mayflower Hospital, Bolton Road, Bury BL8 2BS. Tel: 0161761 6039; fax: 0161761 6035

Mental Health Services for Deaf People, Denmark House, Queen Elizabeth Psychiatric Hospital, Mindelsohn Way, Edgbaston, Birmingham B15 2QZ. Tel: 0121627 2935; Minicom: 0121627 2934; fax: 01216272934

National Deaf Services, South West London and St George's Mental Health Services NHS Trust, Old Church, 146a Bedford Hill, Balham, London SW12 9HW. Tel: 0208675 2100; Minicom: 0208675 2200; fax: 02086752266 
Table 1 Language options for deaf children - the controversial issues

Oralism

It is a hearing world. Most, if not all, deaf children can speak

Sign is not a 'proper' language

Delay in speaking is not important

Signing will prevent speech

Signing will confine a deaf person to a limited life

\section{Signing/English (written and/or spoken) bilingualism}

Oralism can lead to unacceptable failures and delays. 'The deaf are virtually the only neurologically normal people who make it to adulthood without having acquired a first language' (Pinker, 1994)

Sign has the same structures and mechanisms as spoken languages and is processed in the same area of the brain

The 'critical period' for first language acquisition peaks at about 3 years old. Signing allows this to happen on time

There is no evidence for this belief when bilingual principles are applied to development

Deaf signers have a positive self-identity and the confidence to function in the deaf and hearing worlds include a major training programme for staff, both deaf and hearing, for the delivery of primary and secondary services on a more local basis.

At present there is only one specialist mental health service for deaf children and adolescents, based in London, but child psychiatrists in other cities (e.g. Manchester, Birmingham and York) have an interest in seeing deaf children, and further developments are planned.

\section{Deaf children and adolescents \\ Early severe and profound deafness}

About one in 1500 children is severely or profoundly deaf from early life owing to causes that include genetic (mainly recessive) factors, to maternal rubella, neonatal jaundice and meningitis. They cannot take natural advantage of the critical early period of language development by hearing their own and others' voices. Deaf children in deaf signing families acquire language (in sign) at the appropriate age, but the $90 \%$ of deaf children who are in hearing families risk significant delays and limitations in language development, with adverse consequences for psychological, emotional, social and educational development.

For centuries, controversy has raged about whether deaf children should be taught spoken or signed language (Sacks, 1989; Ree, 1999). Sign language was banned in UK schools in the 1880s and has reappeared only in the past 20 years (Table 1 ).

The view that deafness is a solvable medical problem has been reinforced by modern developments in hearing aids and paediatric cochlear implants and the mainstreaming of deaf children in schools. There is consequently a risk that issues regarding identity, language development and appropriate peer groups for deaf children are sidelined. Local education authorities decide communication policies, and at present some counties in the UK have strictly 'oral' policies and others have well-developed
signing/English bilingual programmes. There are still a few residential deaf schools. They provide outof-area placements for children whose parents want an approach that differs from that of the county in which they live. Most also take deaf pupils who have additional problems.

Deaf children have an increased prevalence of mental health problems $(45-50 \% v$. an average of about $25 \%$ for the general population; Hindley et al, 1994; Hindley, 2000). Reasons for this include:

- an excess of organic problems (usually due to the cause of the deafness);

- an excess of emotional, psychological and behavioural disorders;

- delays in access to service, which increase the duration of mental health problems.

In the past, these factors compounded. Conditions such as mild-to-moderate learning disability, attention-deficit disorder and autism were not detected as the children's problems were attributed to their deafness. There were low expectations of all deaf children and the difficulties of teaching them to speak took precedence over successful education and emotional development. Conrad (1977) showed that deaf school leavers had an average reading age of 8-9 years. Gregory, in Deaf Children and their Families (1995) and its follow up volume Deaf Young People and their Families (Gregory et al, 1995), showed the human cost of old-fashioned educational policies. Nearly $20 \%$ of a cohort of deaf young people who had a normal IQ score were unable to complete an interview in either speech or sign.

Some psychiatrists concluded that troubled young deaf people had a specific syndrome, which Basilier (1964) called 'surdophrenia' ('deaf mind'). However, deaf children from deaf families do not show this increased level of mental health problems.

Deaf children, particularly those from hearing families, may be exposed to an excess of the risk factors that can affect all children and lead to adjustment disorders in adolescence. These factors 
include academic failure, low self-esteem, rejecting relationships, inconsistent discipline, failure of ageappropriate development, and abuse (sexual, physical and emotional). Most of these are secondary to negative attitudes to deafness and, above all, to failure to develop age-appropriate communication. Unfortunately, old controversies about educational strategies persist, but neonatal screening, increasing awareness of communication choices and better monitoring of deaf children's early development (including their progress in speech and/or sign) should prevent the extreme delays in language development seen in the past. Personal development programmes in schools and better mental health services should mean that deaf children have access to prevention, assessment and treatment of their problems before they escalate and persist into adult life. In both areas, it is vital to employ deaf professional staff.

\section{Children and adolescents with partial or intermittent deafness}

Children with intermittent deafness, for example because of glue ear, can show emotional and behavioural problems when their hearing is reduced. They feel uncertain, frustrated and left out.

Children with ongoing partial deafness may benefit greatly from hearing aids and usually develop good speech. However, background noise and group interactions can create many problems. Virtually all partially deaf children are placed in mainstream schools, with or without support from a special unit, teachers or communicators. The deaf child is often the only one in his or her class or year and is at risk of being isolated, teased or bullied. Children can internalise negative attitudes that they perceive in others, and low self-esteem can lead to further difficulties in the transition to adult life. Young people with such hearing difficulties can be left feeling that they do not belong with either deaf or hearing people.

\section{Acquired deafness}

People who became deaf in adult life usually consider this in purely negative terms. They are unlikely to learn sign language or to join the deaf community. Deafened people often undergo a bereavement reaction and, unless they can work through this, they may be left with anger and denial. Many people do not make the necessary practical adjustments to their lives because of reluctance to acknowledge the extent of their hearing loss. Problems due to deafness in old age may be missed or attributed to depression or dementia. Because two-way communication is affected, a deafened person's family and friends may become frustrated, and the risk of social withdrawal is increased. Even with an aid or implant, speech reception is not clear and background noise is intrusive. Group conversations can be almost impossible and music is just a noise. In these circumstances, depressive illness may be missed.

Paranoid symptoms have been described in acquired deafness (Eastwood et al, 1985). The deafened person feels increasingly vulnerable and isolated, often uncertain about what is happening. Depression and memory problems due to the depression itself, to head injury (perhaps the cause of the deafness) or to any coexisting dementia increase the risk of paranoid symptoms.

A deafened person needs factual advice and emotional support. Any depressive illness should be fully treated. The National Association of Deafened People and the Royal National Institute for the Deaf (RNID) are valuable sources of information and advice.

\section{Mental health problems in deaf adults}

There can be many difficulties and delays before deaf adults are seen by appropriate mental health services. However, the nature and level of mental health problems are similar to those in the general population, with some excess of organic disorders and emotional and psychological problems.

\section{Organic disorders}

Neurological problems associated with the cause of deafness can have disproportionately adverse effects for deaf people. Cerebral palsy can limit speech, signing and writing. Epilepsy may reduce a person's confidence and increase overprotectiveness from others. Medication may be poorly managed because of limited access to doctors and inability to challenge their decisions.

Some rare neurological disorders such as neurofibromatosis and Schilder's disease and can lead to progressive deafness, with or without blindness. These disorders can cause psychiatric symptoms, including mood disturbance, hallucinations and dementia, which may present before or after diagnosis of the underlying cause.

\section{Schizophrenia}

Deaf people have the same incidence of schizophrenic illness as the general population. They can be diagnosed by means of the same criteria used for hearing people, but extreme care is essential. 


\section{Delusional beliefs}

Many deaf people have had an inadequate education. They also miss 'overheard' background information. Poor literacy may limit information gained from newspapers and subtitled television. Strange 'beliefs' may therefore be due to misunderstandings and gaps in general knowledge. Deaf people may have apparently bizarre ideas about the way their bodies work or about electricity ('it comes out of the wall'), the police ('they broadcast from their radios') or medical procedures such as an electroencephalogram ('I had metal wires put in my head'). As for any patient, the form as well as the content of the belief is important.

\section{Hallucinations}

Deaf people with schizophrenia experience hallucinations in all modalities, including auditory (du Feu \& McKenna, 1999). With careful history-taking, deaf patients are able to describe 'voices' that they 'hear'. The voices, which they usually find unpleasant, have all the characteristics described by hearing people with schizophrenia. Deaf patients often 'recognise' the voices as those of family members or strangers whom they have actually never heard. They can sometimes localise the voices to places or to parts of their own body, something which cannot normally be conceived by a deaf person. They have described noises like 'drumming' or 'Chinese music'. They have given explanations such as 'God made me hear' or 'the voices come on motorbikes'. Sometimes auditory hallucinations are triggered by tinnitus.

\section{Thought disorder}

This can be very difficult to assess, even for clinicians fluent in BSL (Thacker, 1994). The patient's own language level, in sign, speech or writing, may be limited or idiosyncratic. Written English can be poorly developed, or presented in BSL word order, which gives the appearance of disordered thought. Deaf staff with BSL as their first language play a vital part in the assessment. Sometimes the extent of a thought disorder is apparent only as the patient's communication improves with treatment.

\section{Mood and emotional disorders}

In the past, clinicians believed that deaf people showed a low incidence of affective disorder, particularly depression. In fact, deaf people who were depressed were simply less likely to present for help.
Case history A

A 28-year-old deaf man was remanded on a charge of criminal damage. He set fire to the mattress in his cell. He was estranged from his family, but his social worker gave a long history of frequent moves and job losses. At times, he had been overexcited and irritable, frequently visiting the social work office and becoming disruptive. At other times, he was withdrawn and stayed in bed for long periods, rarely going out. Affective disorder was diagnosed. His offence had occurred during a hypomanic episode.

Deaf adults may present with difficulties that stem from childhood experiences. Case history B tells a common story.

\section{Case history B}

A 28-year-old deaf woman, living with her (hearing) parents, became increasingly unhappy and was misusing alcohol. She was aggressive to her parents when challenged. She was born profoundly deaf as a result of maternal rubella but her deafness was not diagnosed until she was 3 years old. Her parents had been strongly advised not to use sign language with her. She was unhappy at her local school and developed behavioural problems. At 7 years of age, she knew only a few words. She went to residential school and was taught by the oral method. Initially, upset at leaving home, she became passive and withdrawn. Her parents thought she had settled in well. She passed art ' $O$ ' level. She returned to live at home. She tried to go to the local deaf club but knew only a little BSL, picked up from children at school. She was barely literate. She worked for a short time at a supermarket but left as she could not communicate with other workers and lost her temper.

On admission, she was hostile and withdrawn. Her parents were frustrated by their poor communication with her. They asked the doctor to sign to her that they loved her. The young woman signed back bitterly that she had wasted her childhood trying to learn to speak and her parents had not spent a single hour learning to sign. Her parents said they had followed the advice they had been given.

Eventually, in a signing environment, with positive role models from deaf staff, the woman accepted help with living skills, literacy and numeracy, assertiveness, relaxation, alcohol education and counselling. She moved on to a rehabilitation programme and independent living.

\section{Personality disorders}

Throughout history, deaf people have been given various personality 'labels', most of which are contradictory. Sign is very expressive, and linguistic facial expressions may be mistaken for emotional ones. Energetic signing may make people appear to be excitable or aggressive. Deaf people's eye contact, use of personal space and way of touching others to gain attention may all be misinterpreted, as they can 
appear direct or intrusive. In addition, the difficulties that were secondary to childhood deprivations and to emotional or psychological problems were considered to be intrinsic to a 'deaf personality'.

Deaf people have therefore been described as impulsive, egocentric, concrete, withdrawn, over- or under-emotional - the list is almost endless. In fact, deaf people have a range of normal personalities but, as in any culture, individuals can express them differently. A deaf person may, of course, have a disordered personality and this can be particularly important in a forensic assessment. Experience, good communication and extreme care are vital before such a diagnosis is made.

\section{Interpreters}

The Disability Discrimination Act requires that public services such as the NHS provide appropriate access for people with disabilities, including communication support for deaf people. However, there is a national shortage of registered BSL interpreters. All too often, a BSL user has to take a relative, even a child, to a doctor's appointment. Apart from issues of appropriateness and confidentiality, these relatives are often not competent signers and information is distorted or missed.

Many problems can arise in a mental health assessment in these circumstances. An interpreter who is inexperienced in such situations may inadvertently gloss over significant symptoms. The interviewer may ask questions that do not translate easily into BSL. Nuances about the speed and nature of the signing, equivalent to pressure or poverty of speech, for example, will be missed. Where the deaf person has limited or idiosyncratic signing, it is not the interpreter's role to comment on this, except to point out when communication is not effective.

In therapeutic interviews, the presence of an interpreter can skew the relationship with the clinician. It is therefore best to book a regular interpreter whom the patient finds acceptable. For a Mental Health Act assessment, a social worker for the deaf should be involved, in addition to the interpreter.

Problems are illustrated in case history C.

\section{Case history C}

A young deaf woman with learning disability was appealing against her detention under the Mental Health Act 1983. She had limited BSL skills. In the tribunal, the interpreter saw her indicate that she was worried by people passing the glass-panelled door of the room. He told the tribunal that she was 'distracted by people in her peripheral vision and concerned about her privacy'. The tribunal members, thinking that the woman had expressed herself in these terms in BSL, doubted that the diagnosis of learning disability was correct and postponed the hearing for a new cognitive assessment.

\section{Visual impairment}

'No two blind people are alike... Blindness is often perceived by the sighted as an either/or condition: one sees or one does not see. But often a blind person experiences a series of veils: I stare at the world through smeared and broken window panes' (Kuusisto, 1998: p. 5).

Although people can be registered as blind or partially sighted, official figures greatly underrepresent the prevalence (Bruce et al, 1991; Walker et al, 1992). There are many more than the estimated 300000 blind people and 500000 partially sighted people in the UK. The most common identified causes are cataract and glaucoma. Less than $10 \%$ of people have their blindness from birth. Functional vision is more important than objective measurement. Field restrictions or poor light can potentiate perceptual loss. There may be a significant difference between near and distance vision and many people with visual impairment can read normal or enlarged print, usually with vision aids. There are 13000 active Braille users in the UK.

In the past, blind people had little access to education. They were often cared for in institutions and trained only for manual work. Low expectations and underemployment still persist.

Nearly half of those over 16 years of age who are registered blind or partially sighted live alone. Older people are much less likely to ask for help such as mobility services and Braille training, vision aids or talking books.

The Disability Discrimination Act should improve attitudes, access, and facilities for blind and partially sighted people to play a full role in society.

There are no specialist mental health services for people with visual impairment, as communication barriers such as those caused by deafness do not arise. However, many teachers, social workers and voluntary organisations provide a counselling role and deserve more support from mainstream services. Well-planned programmes to address emotional, social and practical needs of blind people make an enormous contribution to them and their families.

\section{Children with visual impairment}

Up to half of children who are blind from birth have other disabilities that can limit their potential. The families of all children with visual impairment need early intervention and psychological and emotional support.

As children learn by collating information from different sensory sources and from imitation and 
feedback from others, the development of children with visual impairment may be temporarily delayed in several areas (Tobin, 1998). These include spatial awareness, exploratory crawling and walking, facial expressiveness, attachment and imitation behaviours, extension of language to generalise from one object to another, some cognitive tasks such as Piaget's conservation of mass, and development of a sense of self in comparison with others.

Blind children have to learn the norms of a sighted world. They cannot assess other people's appearance or respond to their body language, but they are expected to look presentable, to face people instead of turning to listen better and to limit unacceptable movements or mannerisms such as touching people. This 'social training' should avoid denial of the children's feelings and should not be perceived as negative or critical. Blind children become aware of their difference from sighted people and may know that this distresses their parents (Parmar \& Gingell, 1996). They may perceive attitudes of rejection or overprotection and the transitions experienced during adolescence can bring emotional problems to the surface.

Fewer blind children go to special schools than did previously. This can limit their specialist training in Braille and mobility and their access to a peer-group and role models. However, inclusion in mainstream schools can increase expectations and break stereotypes.

Most school leavers with visual impairment but no additional disabilities have good literacy, about $80 \%$ with print and $20 \%$ with Braille. Young people have an active social life, including taking part in sport, and increasing access to higher education.

\section{Acquired visual impairment}

Sight loss, particularly when rapid, can precipitate a bereavement reaction. Often, practical help is accepted only after a person is ready to move into an altered way of life. Specific losses, or the fear of them, may be worse for some individuals than for others. The loss of reading and of independent travel are significant thresholds. People with acquired visual impairment face repeated conflicts between the wish to function independently and the need to ask for help as they make constant efforts to fulfil society's norms. As time passes, they remember people's faces as they were and meet new people who have voices but no faces. People with visual impairment may be anxious about the attitudes of others, whether negative or patronising, or afraid of appearing confused, arrogant or uninterested if they do not respond appropriately. There may be sleep disturbances as diurnal rhythms are lost. Expert treatment with melatonin can be effective. There is a significant risk of depression, which may be unrecognised and untreated.

Difficulties are compounded in old age, particularly when there are other health problems or disabilities.

\section{Deaf-blindness}

There are more than 23000 deaf-blind people in the UK. Loss of both hearing and sight may be coincidental or linked to the same cause. The effect on individuals will depend on their age and the speed and degree of loss. Deaf people rely on vision and blind people on hearing, so dual sensory loss has a multiplying effect.

Many children who are deaf-blind because of causes such as meningitis, rubella and extreme prematurity also have learning disability. Communication is severely limited, except by tactile means. However, with intensive input, children can develop structured lives, with practical and social skills, meaningful relationships and pleasurable activities. Behavioural approaches can curtail the self-stimulating and repetitive behaviours that may occur. Families need early information and ongoing support. Deafblind UK (http://www.deafblind. org.uk/) and Sense (http://www.sense.org.uk/ homepage.html) provide a range of advisory, outreach and residential services for deaf/blind people.

\section{Usher syndrome}

Between $5 \%$ and $10 \%$ of congenitally deaf people have Usher syndrome, a recessive genetic condition which, in addition to deafness, causes progressive retinitis pigmentosa (Box 3). This leads to night blindness, tunnel vision and, eventually, severe or total blindness in middle age.

\section{Box 3 Usher syndrome types}

Type I

Profound-to-severe deafness from birth. Retinitis pigmentosa from teenage years. Vestibular dysfunction. Balance problems worsen as sight deteriorates

Type II

Mild-to-severe congenital deafness. Retinitis pigmentosa as Type I

Type III (rare)

Normal hearing at birth. Progressive hearing loss and retinitis pigmentosa, usually from early adult life 
The diagnosis of Usher syndrome is often delayed (Case history D) and may be badly handled (Case history E). Sometimes only the family is told the diagnosis, and the young person is denied the opportunity to come to terms with the prognosis.

\section{Case history D}

A young deaf mother was admitted to a mother and baby unit for assessment. She was ignoring her baby when he was obviously distressed. It transpired that she could not see him unless he was directly in front of her. Usher syndrome was diagnosed.

\section{Case history E}

A 12-year-old deaf girl was assessed in an ophthalmology department. The staff told her parents that they would send the test results to the general practitioner. Across the room, the girl lip read the clinician saying to a colleague, 'She's going to go blind'.

\section{The phases and consequences of Usher syndrome}

A person with Usher syndrome may pass through phases of denial, anger, fear and loss. Counselling, peer-group support and practical help should be given (Miner, 1999). Many people describe their lives with Usher syndrome as a journey, and a mentor with more advanced Usher syndrome can be a guide. Deaf signers can learn 'hands-on' signing and finger-spelling. Cochlear implants can help people who use speech and have types II and III Usher syndrome. However, Braille is hard to learn in later life and people with type I Usher syndrome may have limited literacy. Environmental adjustments such as good lighting and contrasting colours, vibrating pagers and mobility training can all aid independence.

Times of significant deterioration in hearing or sight can lead to acute episodes of anxiety or depression. In addition, a specific psychosis can occur in Usher syndrome (Hallgren, 1959). Visual disturbances and auditory misinterpretations should not be mistaken for hallucinations but it is important that a psychotic illness is not missed because of communication problems.

\section{References}

Basilier, T. (1964) Surdophrenia: the psychic consequences of congenital or early acquired deafness. Some theoretical and clinical considerations. Acta Psychiatrica Scandinavica, 40 (suppl. 180), 363-372.

Bruce, I., McKennell, A. \& Walker, E. (1991) Blind and Partially Sighted Adults in Britain: the RNIB Survey (Vol 1). London: Stationery Office.

Conrad, R. (1977) The reading ability of deaf school-leavers. British Journal of Educational Psychology, 47, 138-148.

Denmark, J. C. (1985) A study of 250 patients referred to a department of psychiatry for the deaf. British Journal of Psychiatry, 146, 282-286.
* - (1994) Deafness and Mental Health. London: Jessica Kingsley Publishers.

Department of Health (2002) A Sign of the Times. London: Department of Health.

*du Feu, M. \& McKenna, P. (1999) Prelingually profoundly deaf schizophrenic patients who hear voices: a phenomenological analysis. Acta Psychiatrica Scandinavica, 97, 1-9.

Eastwood, M. R., Corbin, S. L., Reed, M., et al (1985) Acquired hearing loss and psychiatric illness: an estimate of prevalence and co-morbidity in a geriatric setting. British Journal of Psychiatry, 147, 552-556.

*Grant, B. (ed.) (1987) The Quiet Ear: Deafness in Literature, p. 37. London: Andre Deutsch.

Gregory, S. (1995) Deaf Children and Their Families. Cambridge: Cambridge University Press.

* - Bishop, J. \& Sheldon, L. (1995) Deaf Young People and Their Families. Developing Understanding. Cambridge: Cambridge University Press.

Hallgren, B. (1959) Retinitis pigmentosa combined with congenital deafness with vestibulo-cerebellar ataxia and mental abnormality in a proportion of cases. A clinical and genetico-statistical study. Acta Psychiatrica Scandinavica, 34 (suppl. 138), 1-97.

*Hindley, P. (2000) Child and adolescent psychiatry. In Mental Health and Deafness (eds P. Hindley \& N. Kitson), chapter 3. London: Whurr Publishers.

- Hill, P. D., McGuigan, S. \& Kitson, N. (1994) Psychiatric disorder in deaf and hearing impaired children and young people: A prevalence study. Journal of Psychiatry and Psychology, 35, 917-934.

*Kuusisto, S. (1998) Planet of the Blind. London: Faber \& Faber.

Miner, I. D. (1999) Psychotherapy for people with Usher's syndrome. In Psychotherapy with Deaf Clients in Diverse Groups (ed. I. W. Leigh), pp. 307-327. Washington, DC: Gallaudet University Press.

Mishcon, J., Sensky, T., Lindsey, M., et al (2000) Report of the Independent Inquiry Team into the Care and Treatment of Daniel Joseph. London: Merton, Sutton and Wandsworth \& Lambeth, Southwark and Lewisham Health Authorities.

Parmar, R. \& Gingell, K. (1996) Psychotherapy with children who are blind. Clinical Child Psychology and Psychiatry, 1, 275-282.

*Pinker, S. (1994) The Language Instinct. London: Penguin.

Ree, J. (1999) I See a Voice - Language, Deafness and the Senses - A Philosophical History. London: Harper Collins.

Roberts, J. (1990) A deaf world in Rampton Hospital. Psychiatric Bulletin, 14, 279-281.

*Sacks, O. (1989) Seeing Voices. London: Picador.

Thacker, A. J. (1994) Formal communication disorder. Sign language in deaf people with schizophrenia. British Journal of Psychiatry, 165, 818-823.

Tobin, M. J. (1998) Is blindness a handicap? British Journal of Special Education, 25, 107-113.

Walker, E., Tobin, M. \& McKennell, A. (1992) Blind and Partially Sighted Children in Britain: the RNIB Survey, Vol. 2. London: Stationery Office.

* indicates items of particular interest.

\section{Multiple choice questions}

1 The majority of people with significant hearing loss:

a wear hearing aids

b find it easy to lip-read

c feel left out in group situations

d have paranoid symptoms

e frequently visit their general practitioner.

2 British Sign Language:

a is used by most deaf people in the UK

b has always been encouraged in deaf school children

c is processed in the motor cortex 
$\mathrm{d}$ is strongly associated with the culture of the deaf community

e has different syntactic mechanisms from spoken English.

3 Profoundly deaf adults:

a have higher rates of schizophrenia and affective disorders than the general population

b cannot experience auditory hallucinations

c nearly always have fluency in sign language

d have higher rates of organic disorders than the general population

e have a typical 'deaf personality'.

4 Deafness and visual impairment:

a rarely coexist

b multiply, rather than add up, in their effect on a person's life

c are usually well assessed and treated in older adults

$\mathrm{d}$ are unusual in people with learning disability

e mean that psychotherapy is not possible.
5 Visual impairment:

a has the same effects in early or late onset

$\mathrm{b}$ is simply a practical problem

c is usually less sympathetically regarded than deafness

d can be associated with anxiety or depression in later life

e is unlikely to cause any developmental delay in early life.

MCQ answers

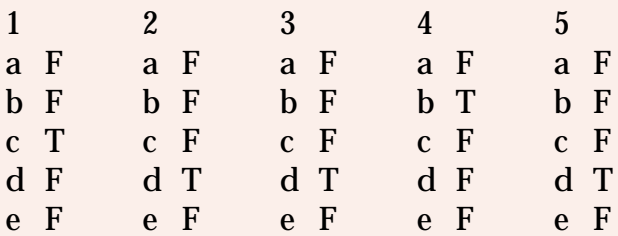

\section{Free speech...}

\section{What do you think about Advances in Psychiatric Treatment - its usefulness for CPD, the new abstracts, the topics covered, the design, PDA downloads?}

Go to:

www.rcpsych.ac.uk/bulletin/apt/apply.htm to join the APT discussion forum and... have your say about APT and CPD! 